\title{
Magnetic Treatment Reduces Water Usage in Irrigation Without Negatively Impacting Yield, Photosynthesis and Nutrient Uptake in Lettuce
}

\author{
Vladimir Zlotopolski \\ United Research Labs, San Marcos, USA
}

Email address:

vzlotopolski@att.net

To cite this article:

Vladimir Zlotopolski. Magnetic Treatment Reduces Water Usage in Irrigation Without Negatively Impacting Yield, Photosynthesis and Nutrient Uptake in Lettuce. International Journal of Applied Agricultural Sciences. Vol. 3, No. 5, 2017, pp. 117-122.

doi: $10.11648 /$ j.ijaas.20170305.13

Received: July 15, 2017; Accepted: July 28, 2017; Published: September 6, 2017

\begin{abstract}
Drought conditions in the Southwestern U. S. and other parts of the world, the potential future impacts of climate change and politically-charged decisions regarding the allocation of water resources continue to challenge the agricultural community to find ways to successfully grow necessary food crops using less irrigation water. In addition, in many parts of the U. S., high levels of certain salts render ground water supplies unusable for salt-sensitive crops. Salt accumulation in soil and in tissues can also be a problem when water conservation methods are applied. Methods that save water and counteract salt accumulation are needed. Historically, magnetic water treatment (MWT) has shown promise in addressing both concerns though results have been inconsistent and somewhat controversial. This study evaluated the effect of MWT on lettuce yield, photosynthetic activity and nutrient levels under various irrigation reduction regimes. In addition, Watermark soil moisture sensors from Irrometer were used to measure the matric potential of root-depth soil of MWT, and non-MWT plants under those same regimes. Results indicated that statistically significant increases in yield, total chlorophyll and concentrations of some macro and micro-nutrients in plants treated by MWT could be achieved while using significantly less water compared to non-MWT irrigation water. In addition, MWT may also help counteract the effect of harmful sodium buildup in plants when less irrigation water was used.
\end{abstract}

Keywords: Magnetic Water Treatment, Agriculture, Crop Yield, Irrigation, Water Treatment

\section{Introduction}

Magnetic water treatment devices were first proposed in 1863 and the first US Patent for water treatment that employed a magnetic field was issued in 1873. However, the use of magnetic fields for the treatment of water remains a controversial issue. In many cases, the field is delivered by permanent magnets in various geometrical configurations while some devices are based on AC, or pulsed fields. Whatever the design, the literature surrounding these devices contain numerous contradictions in claimed effects.

Magnetic water treatment (MWT) is currently being used in over ten countries for a variety of different agricultural reasons, from increased crop yield to faster seed germination [1]. According to some studies, MWT is a technique that achieves high water use efficiency due to its effect on some physical and chemical parameters of water and soil [2]. There are data that indicate that MWT offers many other benefits in agriculture such as increased yield, early maturity and increased fertilizer uptake [1].

It has also been shown that MWT alters the distribution of salts among soil layers, reducing their concentrations in the upper layers, which are more important for agriculture [3].

The effects of MWT and irrigation water salinity on soil moisture distribution in trickle irrigation were investigated [4]. It was shown that mean soil moisture levels at different soil depths below irrigation emitters after MWT were higher than mean soil moisture levels below emitters distributing non-MWT and these differences were significant at the $5 \%$ level. Irrigation with MWT, as compared to non-MWT, increased soil moisture up to $7.5 \%$, and this increase was significant at the $1 \%$ level. According to Bogatin [5], water after magnetic treatment becomes degassed and this degassing increased soil permeability. The strongest leaching 
effect was found for soil samples with soda salinity and for those with chloride and sulfate salinity with some soda. Notwithstanding these results, there are many other articles and papers that claim mostly negative results regarding MWT [6] which is why the subject remains controversial.

This study was carried out to determine whether MWT could reduce the volume of irrigation water used by improving soil moisture retention and/or by enhancing the plant's ability to uptake water without reducing yield.

\section{Materials and Methods}

Lettuce (Lactuca sativa) was cultivated in a greenhouse located in San Marcos, California. Lettuce seeds of a standard commercial variety (Ferry-Morse) were used in the study. Seeds were placed $0.5 \mathrm{~cm}$ deep in cells of polypropylene flats containing watered potting soil. Pots were placed in a greenhouse at a controlled temperature of between $15-25^{\circ} \mathrm{C}$ and a relative humidity of between $40-60 \%$ and were watered once a day by an overhead watering system (about $50 \mathrm{ml} / \mathrm{plant} /$ day). In two weeks, the seedlings were carefully transplanted into $2.5 \mathrm{~L}$ plastic pots containing sandy loam soil in texture, with a $\mathrm{pH}$ of $6.5, \mathrm{EC}$ of $1.4 \mathrm{dS} / \mathrm{cm}$, available $\mathrm{P}$ (Olson-P) of $74 \mathrm{ppm}, \mathrm{NO}-\mathrm{N}$ (2N potassium chloride extraction method) of $24 \mathrm{ppm}$, and extractable $\mathrm{K}$ (ammonium acetate extracting solution) of $141 \mathrm{ppm}$ [7]. The pots were manually watered once a day by potable (tap) water $(\mathrm{EC}, 0.8 \mathrm{mS} / \mathrm{cm}, \mathrm{pH}, 8.2)$ at $0.1 \mathrm{l} / \mathrm{plant} /$ day. This amount was set as a "full rate" $(100 \%)$ of irrigation.

In total, 60 pots were randomly arranged on greenhouse benches. The experimental area was then split into two equal sections. The lettuce plants in the first section received untreated water and the plants in the second section received MWT. Each section had 30 pots which were split into three groups (10 plants per group).

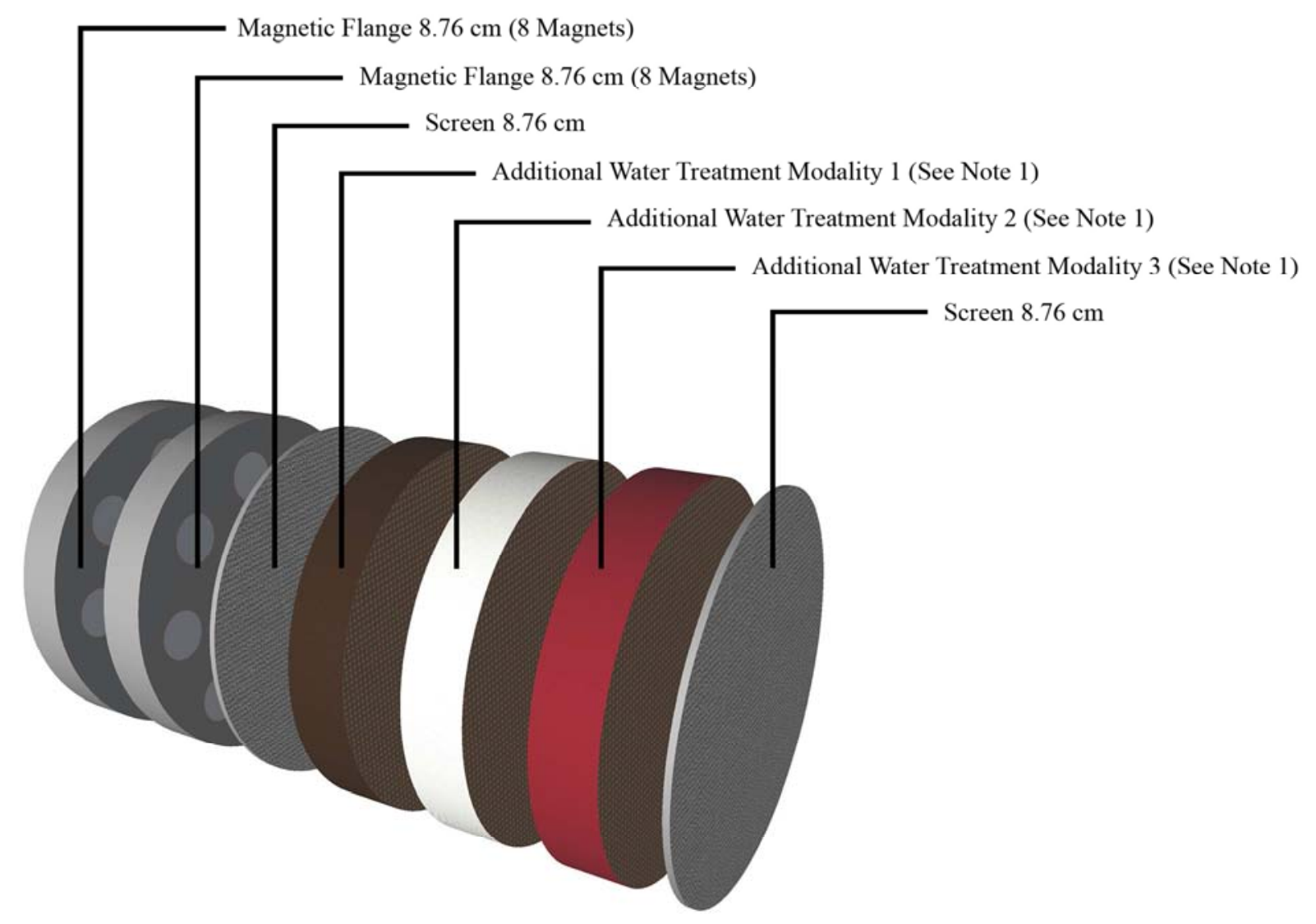

Note 1 - These additional treatment modalities are not researched in this study

Figure 1. Cross section of the Wellpure Water Treatment System.

Different irrigation regimes were then applied to each group. The first group received $100 \%$ of the "full rate" of irrigation water, the second group received $70 \%$, and the third group $50 \%$, of the full rate of irrigation water. These experimental treatment groups were designated C100 (100\% non-MWT), C70 (70\% non-MWT), C50 (50\% non-MWT), T100 (100\% MWT), T70 (70\% MWT), T50 (50\% MWT).
A Model 900M monitor (Watermark) from Irrometer with Watermark Model 200SS soil moisture sensors (also from Irrometer) and temperature compensation sensors were used to read and store data for the experiment. The Watermark Model 200SS is a granular matrix sensor. It consists of concentric, stainless steel electrodes embedded in a referenced matrix material, which is surrounded by a 
synthetic membrane for protection against deterioration. A stainless steel mesh and rubber outer jacket make the sensor more durable than a gypsum block. Movement of water between the soil and the sensor results in changes in electrical resistance between the electrodes in the sensor. The electrical resistance is converted to soil water potential by the Model 900M monitor using a non-linear equation developed by [8] and calibrated to the matrix material contained in the Watermark sensors by Irrometer:

$$
\begin{gathered}
\mathrm{SMP}=(4.093+(3.213 * \mathrm{R}) /(1-(0.009733 * R)- \\
(0.01205 * T)),
\end{gathered}
$$

where SMP - soil matric potential in $\mathrm{kPa} ; \mathrm{R}$ - the sensor resistance (output) in kohms; $\mathrm{T}$ - the soil temperature, ${ }^{\circ} \mathrm{C}$. The Watermark sensor is unique in that it takes its resistive measurement within its defined and consistent internal matrix material, rather than using the surrounding soil as the measurement medium. This unique feature allows the sensor to have a stable and consistent calibration that does not need to be established for every installation.

Each group of plants was assigned a moisture sensor which was placed randomly. Sensors were installed vertically in an active portion of the root zone. Data were collected in two-hour intervals.

The Wellpure Water Treatment System from Wellspring Water Technologies, LLC was used in this study. This system treats water a number of ways, including magnetically. The magnetic component of the system contained 16 ring-shaped, permanent, rare-earth metal magnets placed in two polycarbonate flanges oriented with their respective polarities in opposition to each other (https://www.wellspringwatertechnologies.com). The crosssection of the unit is shown in Figure 1.

The distance between the two flanges was $4 \mathrm{~mm}$ and each magnet had a $12 \mathrm{~mm}$ inner hole. The design forced all water moving through the system to pass through the magnets' inner holes at a velocity of $0.15 \mathrm{~m} / \mathrm{min}$. The magnetic field strength was measured by a Gaussmeter Model GM-2 (AlphaLab Inc.) and it ranged from 3,600 $\mathrm{G}$ (close to the edges) to $700 \mathrm{G}$ (in the middle of the hole) for each magnet. Water passed through the system was collected and immediately applied.

The duration of the experiment was two months with two replications. At the end of the experiment the plants were cut and wet weight was used to determine their yield. The upper leaves were randomly taken from each plant to measure total chlorophyll [9]. A standard leaf analysis was also conducted to determine the concentration of macro - and microelements [10]. A one-way analysis of variance (ANOVA) was used to determine the significant differences between treated and not treated groups of plants. Standard error bars were included.

\section{Results and Discussion}

The results of this study indicated that MWT influenced yield and chlorophyll concentration in leaves. The lettuce yield after the experiment for the three different groups of plants $(100 \%, 70 \%$ and $50 \%$ rates of irrigation) is shown on Figure 2. Although the yield difference at the $100 \%$ rate of irrigation was not statistically significant for the control and treated groups, the yields from the MWT groups were all higher than the control groups and statistically sufficient results were obtained for the $70 \%$, and $50 \%$ rate groups. The most significant effect was obtained for the plants that received the least amount of water (C50/T50). The observed value from $\mathrm{F}$ distribution for this group was 9.11 , while the critical value of $\mathrm{F}$ was $4.41(\mathrm{p}<0.05)$. Moreover, the $70 \%$ MWT treatment group demonstrated a non-statistically significant increased yield compared to the yield of the $100 \%$ control group.

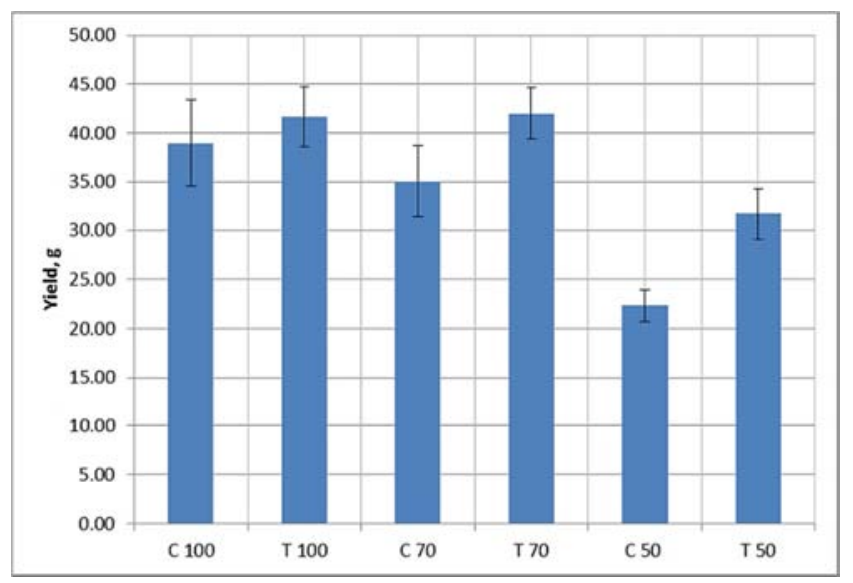

Figure 2. Change in yield with water stress and MWT.

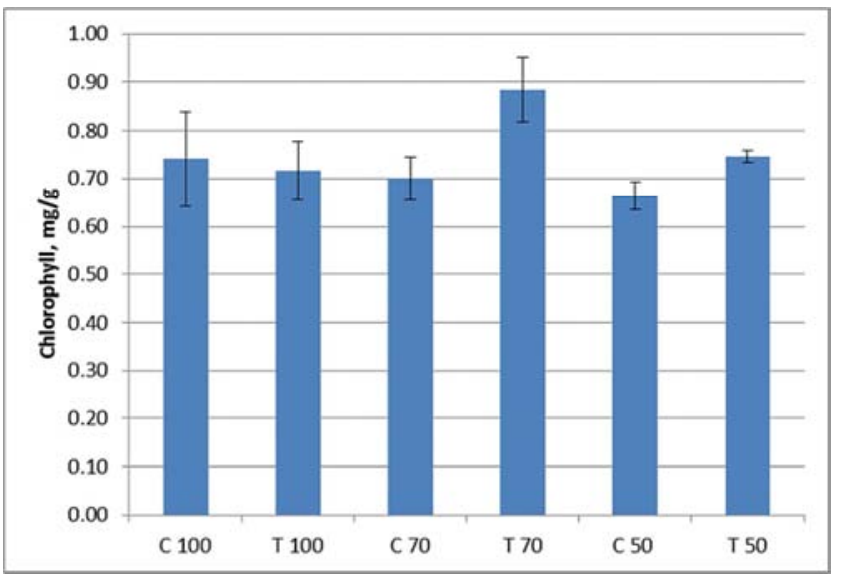

Figure 3. Changes in chlorophyll with MWT and different levels of water stress.

The results in Figure 3 reveal that the amount of total chlorophyll increased in the two groups of MWT-plants (70\% rate and $50 \%$ rate) as compared to the control groups irrigated with non-MWT water. The observed $\mathrm{F}$ values for these groups were 6.10 and 10.0, respectively, compared to a critical $\mathrm{F}$ value of $4.30(\mathrm{P}<0.05)$. The chlorophyll content in the T70 group had the highest chlorophyll value increasing $25.7 \%$ compared to the $\mathrm{C} 70$ control group. These results are in agreement with those obtained by other researchers.

Obviously, the ability of MWT to increase the content of photosynthetic pigments, even under water stress, is 
considered beneficial for plants [11]. Cho [12] has attributed the increase of photosynthetic pigments to a decrease in the amount of manganese in MWT compared to non-MWT treated water [13]. Similarly, Macfie and Taylor [14] have reported that chlorophyll shortages under environmental stress is due to manganese toxicity which leads to a lack of chlorophyll between the veins of leaves and a decrease in photosynthesis as a whole. Faten and Jameel [15] reported that the photosynthetic pigment significantly increased under a static magnetic field. The highest measurements were recorded at $100 \mathrm{mT}$, after 360 minutes of exposure. Significant increases in pigment fractions were recorded in chickpea plants (Cicer arietinum) irrigated with MWT compared to a control treatment. Similar results were observed in rice (Oruza sativa) when irrigated with MWT [16]. Increases in photosynthetic pigments were also recorded in sunflower (Helianthus annuus L.) [17] and soy bean (Glycine max L. Merrill) [18] when seeds or explants were exposed to a magnetic field $(3.8-4.8 \mathrm{mT})$ for a short time.

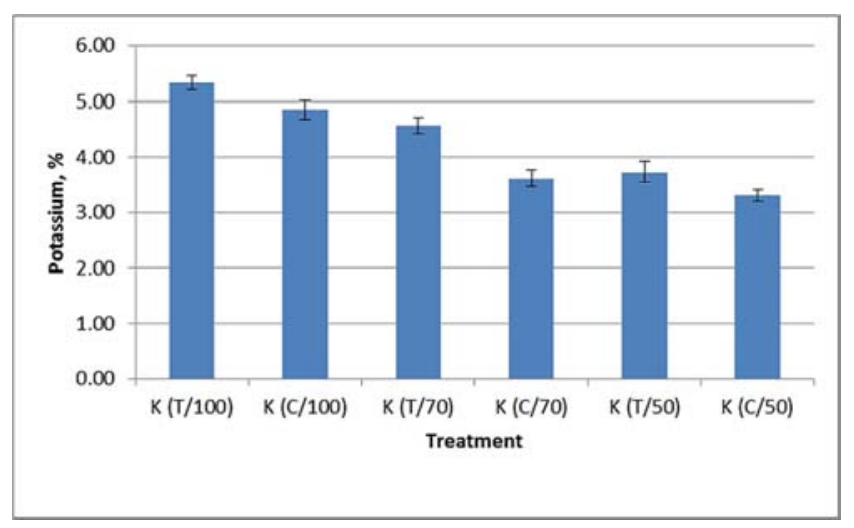

Figure 4. Changes in potassium concentration with MWT and different levels of water stress.

Analysis of macro- and microelements in leaves revealed that concentrations of potassium were decreased with the reduction of irrigation water (Figure 4) for both treatment and control groups. According to [19, 20] concentrations of potassium in jojoba and banana plants were also reduced, respectively, under drought conditions. Similar results were found by Restrepo-Diaz et al. [21] in the leaves of waterstressed olive plants, regardless of nutritional status. Moreover, Al-Khazen et al. [11] showed that water stress also reduced potassium but, adding MWT resulted in almost double the amount of potassium compared to non-MWT water under the same water stress. According to our results, the concentration of potassium was higher in the plants irrigated by MWT (1.42, 1.26 and 1.12 times in C100/T100, C70/T70 and C50/T50 groups, respectively). It therefore appears that potassium levels are reduced under water stress conditions but that MWT offsets this effect, perhaps as a result of its beneficial impact on nutrient uptake, as described below.

It is known that potassium is characterized by high mobility in plants at all levels (within individual cells and tissues as well as in long-distance transport via the xylem and phloem). Potassium is the most abundant cation in the cytoplasm. Importantly, its salts are known to be a major contributor to the osmotic potential of cells and tissues [22]. Many researchers have shown that magnetic treatment changes the physical parameters of water such as surface tension [23], diffusion velocity [19], salts' solubility [24], vibration modes and electrolytic potential [25]. Some of these parameters could impact osmotic potential and therefore nutrient uptake. It has been shown that MWT increases nutrient uptake [26]. Our investigation also revealed an increase in the concentration of some other elements ( $\mathrm{Ca}, \mathrm{Fe}, \mathrm{Mn})$. At the same time, we did not find statistically sufficient differences in $\mathrm{Mg}, \mathrm{Cu}$ and $\mathrm{Zn}$.

Figure 5 shows the concentrations of sodium during the experimental period. The accumulation of sodium in all plants within the control group was significant. The sodium concentration in plants after MWT was $1.50 \%$ for T100, $1.53 \%$ for $\mathrm{T} 70$ and $1.77 \%$ for $\mathrm{T} 50$ groups. The same parameter for plants that received untreated water was $1.47 \%, 1.95 \%$ and $2.46 \%$ respectively.

Thus, the sodium concentration in the MWT group increased only $18 \%$ (1.50\% for T100 and $1.77 \%$ for T50) compared to $67 \%$ for the untreated group $(1.47 \%$ for $\mathrm{C} 100$ and $2.46 \%$ for $\mathrm{C} / 50$ ). According to [20] drought conditions increase $\mathrm{Cl}^{-}$as well as $\mathrm{Na}^{+}$concentrations in both leaves and roots.

MWT reduced sodium concentrations in soil by leaching it below root zones $[3,26]$. This could explain why plants treated by MWT had less leaf sodium levels compared to non-MWT. Another possible explanation may relate to the magnetic properties of these elements. Sodium is a paramagnetic element which has a small, positive susceptibility to magnetic fields. Potassium and other elements are diamagnetic which are slightly repelled by magnetic fields [27].

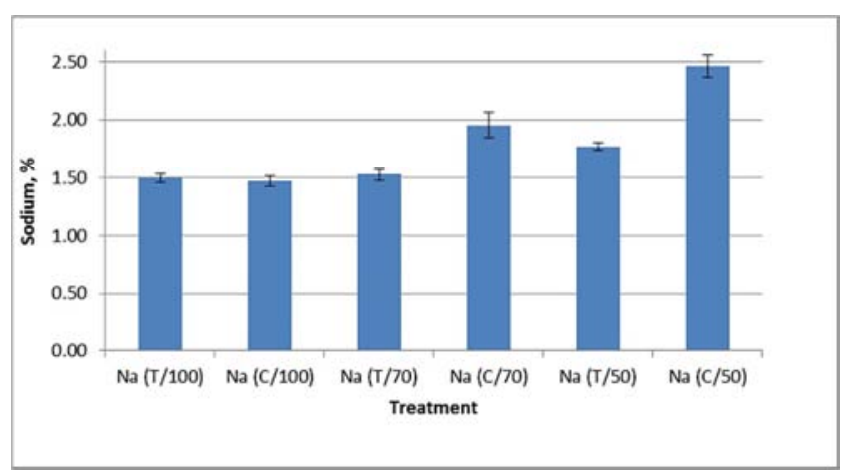

Figure 5. Changes in sodium concentration with MWT and different levels of water stress.

This study demonstrates that MWT can improve water use efficiency. This may be the result of a fundamental change in physical water properties (viscosity, surface tension, permeability and etc.) which could impact osmotic pressure thereby improving the plant's ability to uptake water or these changes may result in improved soil moisture retention. Also 
it may be result of simultaneous changes of water parameters and soil. Previous researchers have claimed that MWT increased the level of water absorption in soil [26].

In this regard, interesting results were obtained by an analysis of data accumulated during this experiment by moisture sensors. Soil matric potential data from this study is presented in Figure 6. Soil matric potential is negative to reflect the fact that energy must be exerted to extract water from the soil and the greater that negative number, the more energy is required to extract the water and thus the drier that soil is. Data revealed that soil irrigated by municipal water after MWT had a less negative soil matric potential compared to the control group indicating that soil irrigated with MWT was wetter than control group soil at the same level of irrigation.
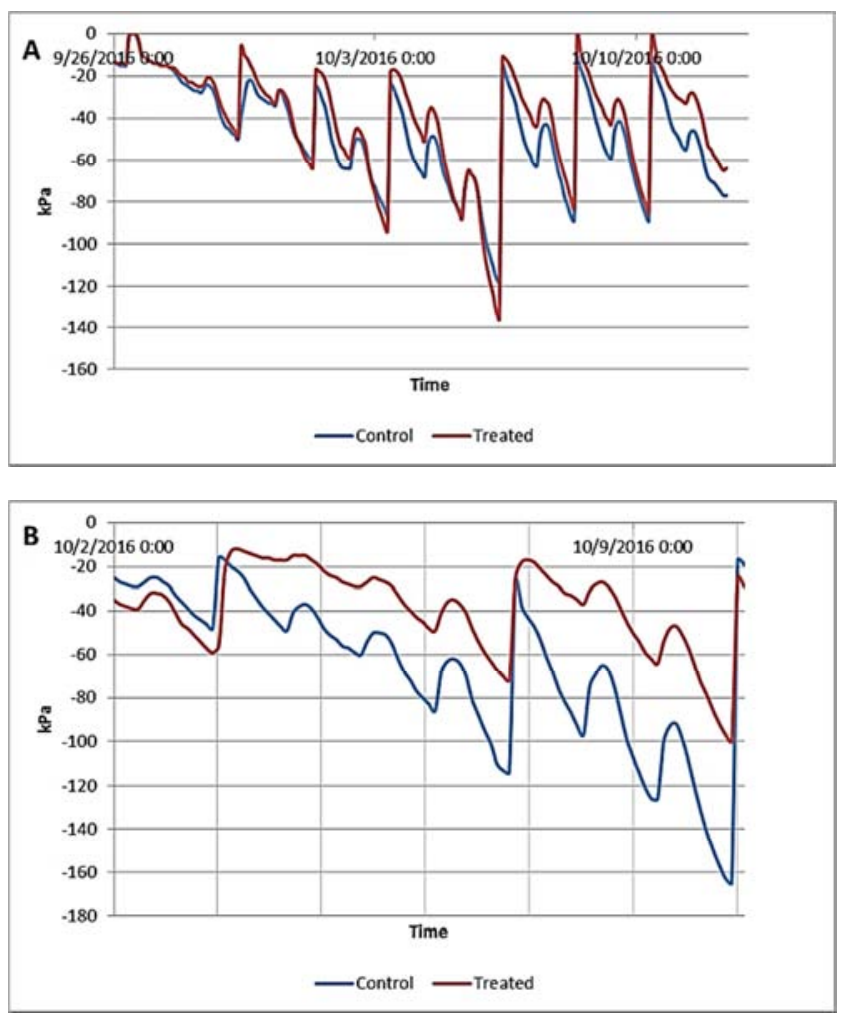

Figure 6. Soil metric potential of soil irrigated regular and treated water.

(A. $100 \%$ "full rate"; B. $50 \%$ of "full rate"; average numbers from two replications).

Data from all three groups $(100 \%, 70 \%, 50 \%)$ of irrigation demonstrated the same relationship. Typical graphs are presented in Figure 6. Figure 6 (A) presents data obtained from soil irrigated at $100 \%$ of the full rate of irrigation. The difference in soil matric potential for T100 and C100 groups was $6.74 \pm 0.54 \mathrm{KPa}$. When irrigation water was reduced the difference in metric potential between control and treated groups increased. The difference in soil matric potential for the T70 and C70 group was $11.11 \pm 0.54 \mathrm{KPa}$ and $16.65 \pm 1.68$ $\mathrm{KPa}$ for the T50 and C50 group (Figure 6, B). The soil matric potential differential for all plant groups irrigated with MWT was statistically significant compared with the plant groups irrigated with non-MWT. The observed value from $\mathrm{F}$ distribution was 14.66 for the T100 and C100 group, 25.63 for the T70 and C70 group, and 34.16 for the T50 and C50 group, while the critical value of $F$ was $6.90(\mathrm{P}<0.01)$.

While additional controlled studies will need to be performed to conclusively prove that MWT improves the ability of all soil types to retain water, we can conclude from the similarity of results obtained for all three types of irrigation schedules $(100 \%, 70 \%$ and $50 \%)$ in this study, that soil matric potential was changed, that this change was beneficial for water content in soil and that the plants observed in the treatment arm of this study appeared to have been benefited by that change.

\section{Conclusions}

This study demonstrated that MWT can reduce the volume of irrigation water without negatively impacting yield, photosynthesis and nutrient uptake. In fact, it was shown that statistically significant increases in yield, total chlorophyll and concentrations of some macro and micronutrients in plants treated by MWT could be achieved while using significantly less water compared to non-MWT irrigation water. In addition, MWT may also help counteract the effect of harmful sodium buildup in plants when less irrigation water is used. Thus, present findings suggest that MWT can be considered an efficient technology that can assist in reducing irrigation water usage. However, the potential of MWT for crop production needs to be studied under field conditions to further evaluate its effects on yield production.

\section{References}

[1] Hizayn M and Qados AMSA. 2010. Irrigation with magnetized water enhances growth, chemical constituent and yield of chickpea. Agriculture and Biology Journal of North America. 1 (4): 671-676.

[2] Noran R, Shani U, Lin I. 1996. The effect of irrigation with magnetically treated water on the translocation of minerals in the soil. Magnetic and Electrical Separation. 7: 109-122.

[3] Zlotopolski V. 2017. The Impact of magnetic water treatment on salt distribution in a large unsaturated soil column. International Soil and Water Conservation Research. http://dx.doi.org/10.1016/j. iswcr.2017.05.009.

[4] Mostafazadeh-Fard B, Khoshravesh M, Mousavi SF, Kiani A R. 2011. Effects of Magnetized Water and Irrigation Water Salinity on Soil Moisture Distribution in Trickle Irrigation. ASCE. Journal of Irrigation and Drainage Engineering, American Society of Civil Engineering. 137 (6): 398-402.

[5] Bogatin J, Bondarenko N, Gak E, Rokhinson E, Ananyev I. 1999. Magnetic Treatment of Irrigation Water: Experimental Results and Application Conditions. Environ. Sci. Technol. 33: $1280-1285$.

[6] Krauter P, Harrar J, Orloff K, Bahowick S. 1996. Test of a Magnetic Device for the Amelioration of Scale Formation at Treatment Facility D, Livermore, California. 
[7] Sparks DL. 1996. Methods of Soil Analysis. Part 3. Chemical Methods. Soil Society of America.

[8] Shock CC, Barnum JM, Seddigh M. 1998. Calibration of Watermark soil moisture sensors for irrigation management, pp. 139-146, Proceedings of the International Irrigation Show, San Diego, CA. Irrigation Association.

[9] Standard Operating Procedure 2030. Chlorophyll Determination. 1994 (https://clu-in.org/download/ert/2030R00.pdf)

[10] Motsara MR. and Roy RN. 2008. Guide to laboratory establishment for plant nutrient analysis. FAO Fertilizer and Plant Nutrition Bulletin, 19.

[11] Al-Khazan M. M, Abdullatif BM, Nabila Al Assaf. 2011. Effect of magnetically treated water on water status, chlorophyll pigments and some elements content of Jojoba (Simmondsia chinensis L.) at different growth stages. African Journal of Environmental Science and Technology. 5 (9): 722731.

[12] Cho CH, Singh S, Robinson, GW. 1996. Liquid water and biological systems: The most important problem in science that hardly anyone wants to see solved. Faraday Discus. 103: 19-27.

[13] Al-Khazan MM, Abdullatif BM. 2009. Effect of irrigation with magnetized water on growth, photosynthesis pigments and proline accumulation in jojoba [plants (Simmondsia chinensis L.) seedlings. Saudi J. Biol. Sci., 16 (3): 107-113.

[14] Macfie SM, Taylor GJ. 1992. The effect of excess Manganese on Photosynthetic rate and concentration of chlorophyll in Triticum aestivum grown in solution culture. Physiol. Planetarium. 85: 467- 475 .

[15] Faten D, Jameel M. 2009. Magnetic Fields Induce Changes in Photosynthetic Pigments Content in Date Palm (Phoenix dactylifera L.) Seedlings. The Open Agriculture Journal, 3: 15 .

[16] Nasher SH. 2008. The Effect of magnetic water on growth of chickpea seeds. Eng. \& Tech. 26 (9): 4 pages.

[17] Oldacay S. and Erdem G. 2002. Evaluation of chlorophyll contents and peroxides activities in I (Helianthus annuus L.) genotypes exposed to radiation and magnetic field. Pak. J. of Appl. Sci. 2 (10): 934-937.

[18] Atak C, Emiroglu O, Aklimanoglu S. and Rzakoulieva A. 2003. Stimulation of regeneration by magnetic field in soybean (Glycine max L. Merrill) tissue cultures. J. Cell Mol. Biol. 2: 113-119.

[19] Gang N, St-Pierre LS, Persinger MA. 2012. Water Dynamics Following Treatment by One Hour 0.16 Tesla Static Magnetic Fields Depends on Exposure Volume. Water. 3: 122-131.

[20] Mahouachi J. 2007. Growth and mineral nutrient content of developing fruit on banana plants (Musa acuminata AAA, 'Grand Nain') subjected to water stress and recovery. Journal of Horticultural Science and Biotechnology. 82: 839-844.

[21] Restrepo-Diaz H, Benlloch M, Fernández-Escobar R. 2008. Plant water stress and $\mathrm{K}^{+}$starvation reduce absorption of foliar applied $\mathrm{K}^{+}$by olive leaves. Scientia Horticulture. 116: 409413.

[22] Marschner H. 1995. Mineral Nutrition of High Plants (2nd Edn), London Academic Press, London.

[23] Young Cho, Sung-Hyuk Lee. 2005. Reduction in the surface tension of water due to physical water treatment for fouling control in heat exchangers. International Communication in Heat and Mass Transfer 32: 1-9.

[24] Musa Tariq N and Hamoshi Ebaa A. 2012. The Effect of Magnetic Field on The Solubility of $\mathrm{NaCl}$ and $\mathrm{CaCl}_{2} \cdot 2 \mathrm{H}_{2} \mathrm{O}$ at Different Temperature and $\mathrm{pH}$ Values. Basrah J. Agric. Sci. 25 (1): 19-26.

[25] Otsuka I, Ozeki S. 2006. Does Magnetic Treatment of Water Change Its Properties? Physical Chemistry B. Letters. 110: 1509-1512.

[26] Yadollahpour A, Rashidi S, Fatemeh K. 2014. Applications of Magnetic Water Technology in Farming and Agriculture Development: A Review of Recent Advances, Current World Environment, 9: 695-703.

[27] Nave CL. 2008. Magnetic Properties of Solids. Hyper Phys. 15: $11-23$. 